Sarina Bakićl

\title{
DEMOKRATIZACIJA KULTURE ILI KULTURA DEMOKRATIJE
}

\begin{abstract}
- Sažetak-
Osnovnopitanjesvakog shvatanja kulture, obrazovanjai demokratijeuopšte jeste pravo svakog čovjeka na obrazovanje i kulturu. Pravo na obrazovanje, kulturu, pravo čovjeka na samopotvrđivanje najbolje je posmatrati kroz vidove njihovih praktičnih ostvarivanja ili njihovih neostvarivanja. Tekst naglašava promišljanje da je opšta demokratizacija kulture iznjedrila i sasvim drugačije pristupe, u smislu mjesta i uloge kulture u životu svakog pojedinca. Također, ovaj tekst nastoji podvući jasne distinkcije između dva glavna društvena obrasca kulturne demokratije i demokratizacije kulture.
\end{abstract}

\section{Ključne riječi: kultura, demokratija, prosvjetiteljstvo, socijalizacija, kulturne potrebe.}

\section{Uvod}

Ono što je danas poznato kao proces demokratizacije kulture samo se površno gledano odnosi na participaciju svih ljudi u aktivnostima koje su se prije isključivo odnosile na društvene elite. Demokratizacija kulture teži promovisanju i realizaciji željenih vrijednosti - jednakosti, dostupnosti, participacije i ljudskih prava.

Tokom posljednjih decenija također smo svjedoci neoliberalnih napora da se kultura podredi ekonomskim mehanizmima slobodnog tržišta u smislu kulturalizacije ekonomije ili, obratno, ekonomizacije kulture. Principi slobodnotržišne konkurencije i poduzetništva uvedeni su u nekada privilegovano polje umjetničke ili intelektualne proizvodnje.

Ovakva logika savremene upotrebe kulture uočljiva je u neoliberalnoj strategiji kulturalizacije političkih odnosa, kako je to formulisao Boris Buden;

1 Mr. sc. Sarina Bakić, Fakultet političkih nauka, Univerzitet u Sarajevu 
ona u manjoj mjeri ukazuje na gotovo potpuni slom ,političke sfere” u njenom modernom smislu, a više na njenu značajnu transformaciju. Artikulacija političkih borbi i društvenih antagonizama izmještena je iz „klasičnog” domena državnih aparata kao što su političke partije, parlamentarni sistem i procedure pravne države ka rasutom polju konkurentskih „kulturnih opcija”. Međutim, kulturalizacija ne znači samo transformisanje političkih problema u probleme kulture. Kulturalizacija podrazumijeva također ,školu kulture": obrazovanje, kultivisanje i uzgajanje subjekata dominantne kulture. Kultura je samim tim samo jedan segment ideološke edukacije ili, još bolje, kreiranja (njemačka riječ Bildung obuhvata oba značenja) „narodnih masa” precizno govoreći, subjekata (u oba značenja te riječi: podanika i autonomnih djelatnika) kapitalističkog sistema. Kultura tolerancije, kultura komunikacije, ekološka kultura, digitalna kultura itd., sve one predstavljaju neoliberalne oblike novog društvenog obrazovanja, onoga što Althusser, naziva savoirfaire (znati-kako-činiti).

Bosanskohercegovačko društvo jeste dobar primjer zamršenosti u ovako teškoj mreži različitih tendencija koje karakterišu savremene procese u kulturi. Teškoće nećemo naći samo u različitim ideološkim opterećenjima ili različitim političkim preferencijama. Suočenost sa posljedicama rata, siromaštvom velikog dijela građana, ekonomskim i kulturnim zaostajanjem, nepismenošću, te strahom od 'drugog' i 'drugačijeg', dodatno usložnjava nimalo jednostavan kulturni kontekst. Veći dio kulture u Bosni i Hercegovini, prvenstveno mislimo na komercijalne vidove kulture, stvara atmosferu bez postojanog kulturnog značenja i razvijanja kulturne svijesti. Ovakva atmosfera, vještački izazvana i vještački održavana, zamagljuje i devalvira autentične kulturne vrijednosti, a sama se, bez duhovnog rizika i stvaralačke odgovornosti, pojavljuje kao kulturni bosanskohercegovački horizont. Atmosfera o kojoj govorimo, bez duhovnih podsticaja i dvosmislenosti stvaralačkog traženja i podsticaja, svojom prividnom, tzv. oslobođenošću kao da ispravlja prirodnu i društvenu nepravdu neobdarenih, netalentovanih i defavoriziranih. Takvi se bez većih poteškoća uključuju u ovu atmosferu, jer osjećaju da im za takvo prisustvo nije potreban nikakav intelektualan rad i napor. Agresivnost i uticaj pseudokulturnih proizvoda u Bosni i Hercegovini uslijedili su, kao i drugdje, tek kada su ovakvi proizvodi dobili ulogu na tržištu, baš kao i svaka druga roba koja se masovno traži, masovno troši i masovno prihvata.

Teme kao što su nedovršeni i fiktivni identiteti, otvaranje prostora za postojanje različitih identiteta, akcentiranje konkretnih ,životnih” problema, pitanja manjina, insistiranje na toleranciji i pristojnosti, doživljavaju se još 
uvijek kao prijetnja nacionalnim identitetima i nacionalističkim politikama i interesima. S druge strane, potrošački mentalitet, popularna i medijska kultura, nove tehnologije, princip ,sve je dozvoljeno” i prateći relativizam vrijednosti uveliko su ušli u bosankohercegovačku svakodnevnicu, kulturu, umjetničke stilove, modne stilove, civilno društvo, javnu sferu i politiku. Nipodaštavanje istorijskih, kulturnih, u nekim slučajevima i tradicionalnih autoriteta, nepostojanje kulturne i klasne stratifikacije društva koja bi predstavljala osnovu kakve-takve društvene strukture, dominacija provincijske političke kulture, stvaraju ambijent koji ne pogoduje ničem drugom do voluntarizmu i potrebi da se ,promjene” definišu na osnovu ličnih interesa, znanja i neznanja, navika i ubjeđenja.

\section{Kultura i jučer i danas}

Otkada je u I vijeku prije nove ere Ciceron u Pismu Tuskulancima prvi $\mathrm{u}$ istoriji upotrijebio riječ kultura (philosophia autem cultura animi), pa sve do danas, provlači se sklonost da se kultura i obrazovanje poistovjećuju s pojmovima humanosti i uzvišenosti, s bogatstvom duha i misli. Ljudi svakodnevno koriste ove pojmove da bi izrazili plemenitost u ponašanju, moć znanja ili, pak, sklad boja i oblika. A isto tako će i pojmove izvedene iz njih izjednačavati sa ne uvijek jasnim ličnim uzorima. Edward Sapir je vjerovatno mislio na isto kada je rekao da riječ kultura označava nejasna i složena područja mišljenja koja se kolebaju, sužavaju ili šire zavisno od stajališta bilo koga ko ih upotrijebi. Međutim, nije teškoća samo u mnogoznačnosti ili nejasnoćama pojmova kultura i obrazovanje, nego i u tome što se oni mistificiraju bar isto toliko koliko i njima blizak pojam demokratije. Spomenuto mistificiranje nalazi osnove u samim ljudima. Savremeni mitovi o kulturi pa i o obrazovanju koriste metafore, koje imaju moć ogromnog uticaja na ljude i ostvaruju vezu s njihovim najintimnijim težnjama i željama. Tako, uprkos modernoj tehnologiji koja ih osporava, mitovi o kulturi i obrazovanju opstaju, jer poniču na plodnom tlu ljudskih želja, težnji, uobrazilja, straha i nesigurnosti.

Prosvjetitelji su doprinijeli da se ovakvo značenje kulture i obrazovanja održava i među intelektualcima i umjetnicima, koji ga estetički, istorijski i sociološki razrađuju da bi ga na isti način slobodno kao i popularne predstave izjednačavali sa visoko intelektualnim zahtjevima, sa kulturom duha. Koliko intelektualaca i umjetnika poistovjećuje kulturu i obrazovanje s istančanim etičkim i estetskim osjećanjima i vrijednostima, s idealom? A preostaje i praktičan pogled: svakodnevni i oni drugi kulturni poduhvati koje pokreće briga za druge, da se drugi kulturno i duhovno obogate i da se na taj način 
mijenjaju i preobražavaju. Shvatanje kulture i obrazovanja jeste njegovo usmjeravanje i ka pomenutom praktičnom pogledu, $i$ to ne samo radi promišljanja i kontemplacije nego ponajviše zbog društvene potrebe. Trebalo bi se podsjetiti da su prosvjetitelji živjeli u epohi kapitalističkog razdvajanja individualnog od kolektivnog, duhovnog od materijalnog te da je zato njihovo shvatanje etičko. Prosvjetitelji su prepoznali društvenu potrebu kao proturječje na individualnom planu: između želje da se samostalno razvija i napreduje i neostvarivosti ovih težnji u kapitalističkoj ekonomiji i partikularističkim društvenim uslovima. U takvim okolnostima, kakva bi druga solucija ovog proturječja mogla biti ako ne ona u obrazovanju i kulturi koja je u stanju da čovjeka oslobodi i izdigne ga u odnosu na realnost. Usvajajući kulturu i pokušavajući spoznati preko nje istinu, dobrotu, ljepotu, čovjek prevladava ograničenost svog stvarnog postojanja, ostvaruje jedinstvo s prošlošću i sadašnjošću.

Prosvjetiteljsko poimanje kulture i obrazovanja je, tako, još od početka predodređeno da bude humanističko i etičko. Tek kasnije, Marx će u Tezama o Feuerbachu ukazati na drugu mogućnost: da se svijet ne samo oblikuje u duhovne projekcije i različito tumači već i da se mijenja. Ova ideja o promjenama, koju možemo smatrati početkom novog shvatanja kulture, sadržavala je u sebi izrazito antiprosvjetiteljski stav: poziv, ne da se čovjek obrazuje i bježi iz stvarnosti, već da proniče u tu stvarnost i spoznaje kako bi je mogao mijenjati. Sto godina prije Marxa, Rousseau je preporučivao izlaz iz začaranog kruga kapitalističke stvarnosti putem napuštanja industrijske civilizacije i vraćanja prirodi. Ovaj njegov prijedlog Voltaire je izložio sramu rekavši da Rousseau poziva ljude ,da pasu travu”. Kod romantičara, koji između života i obrazovanja i kulture vide raskorak koji se produbljuje, kultura i nauka se poimaju i kao bjekstvo u razmišljanje. Misao o kulturnom i intelektualnom eskapizmu prvi je spomenuo Montaigne, što se odnosilo na pozorište i književnost. Pola vijeka kasnije, Pascal preuzima ovo mišljenje, ali zato da bi ga promijenio, bjekstvo se kod njega više ne odnosi na pozorište i književnost već na čistu kontemplaciju. Umjesto odlaska u pozorište i čitanja koje je preporučivao Montaigne, Pascal ljudima savjetuje da sjede u svojim sobama i „postanu kulturni” tako što će razmišljati ko su, šta su, odakle su i kuda idu.

Ne prepoznajemo li ovu prosvjetiteljsku misao o kulturi i obrazovanju, ili bar njene značajne tragove, i u savremenim mitovima o obrazovanju i kulturi? Zatim, onaj isti odnos i predstavu o životu, isto ono shvatanje kulture i obrazovanja kao prilagođavanja, kao spiritualizovanje stvarnosti i nadoknade 
za „bjekstvo od života”. „Ako je život cilj”, kako je pisao Danilo Kiš, „umjetnost je život”. Ako je život vezan za sat, umjetnost je spontana i, bar naizgled, neinhibirana. Na spoljašnjem, senzualnom planu, kultura i umjetnost unose u život različitosti i raznovrsnosti, unose boje i melodije. Scenografija u pozorištu, suptilne ili jake, izazovne boje na platnima, psihološka stanja karaktera u romanima i filmovima, neuobičajeni spojevi zvukova u muzici, sve to djeluje drugačije u odnosu na stvarni život. Način kulturne potrošnje i način obrazovanja u kome se čovjek angažuje je jednostavno odraz njegove individualnosti.

Šta se bitno promijenilo od perioda Montaignea, koji je gotovo na isti način vidio kulturu kao ‘sklonište', čak i kao moguću psihoterapiju? Da li bismo ovu sličnost objasnili kao podudarnost ili kao uslovljenost, ali kakvu? Očigledno je da se niti podudarnost niti uslovljenost samom kulturom ne mogu objasniti, ostaje još da povjerujemo kako se istorija stvarno ponavlja. Međutim, razlike ipak postoje. U okviru prosvjetiteljskog načina mišljenja, mitovi o kulturi, obrazovanju i umjetnosti se mijenjaju, ali samo zato da bi zadržali isti moralni i 'utješiteljski' sadržaj. Naprimjer, posljednji mit o kulturi kao kvalitetu života, ili najnovija doktrina socio-kulturnih animacija, ne označavaju li oni stalno nešto novo, uz nepromijenjene okolnosti i uslove života? Sjetimo se one pesimistične francuske poslovice „Plus qa change, plus c'est la meme chose" ". Po čemu se savremeni mitovi razlikuju od Montaigneovih? Prava, 'živa' kultura je, misle stari prosvjetitelji a uvjeravaju nas u to i savremeni, sinonim humanizma, obrazovanja, istančanog osjećaja i produbljenog načina mišljenja. To je, kako kažu, pravi život koji bi se trebao prvo spoznati a onda živjeti. Potrebno je ovdje primijetiti da je ,spoznati” ključna riječ.

Prosvjetiteljsko poimanje kulture i obrazovanja je, dakle, bilo i ostalo moralističko, njen se strogi moral uzdiže iznad nemoralnosti čovjekovog položaja. Ova filozofija nije usmjerena na to da nešto mijenja u čovjekovom životu, ili barem ne puno, nego na unutrašnje mijenjanje čovjeka, na njegovo prilagođavanje. Obrazovanje i kultura je u ovim tumačenjima ideja o promjenama, ali o promjenama u samom čovjeku, a ne u objektivnom svijetu. Ovakva filozofija proizvodi ideje kojima se preporučuje mirenje sa stvarnošću na taj način što se stvarnosti suprotstavlja nadstvarnost - lijepo, uzvišeno i plemenito u odnosu na ne-lijepo, ne-uzvišeno i ne-plemenito. Marcuse je u pravu, kultura, ona vladajuća i prosvjetiteljska, nije osporavajuća, ona je uvijek bila afirmativna, ali važno je reći da je uz sve promjene ona i dalje ostala takva. Nakon ovog upoređivanja u istorijskom kontekstu, nema

2 „Što se stvari više mijenjaju, više ostaju iste.” 
nikakve sumnje: onog trenutka kada se opravda potreba za obrazovanjem, podučavanjem i usmjeravanjem ljudi, i kada kultura i obrazovanje postanu sredstvo tog usmjeravanja, nastupaju nepredvidive posljedice i dešavanja sa čovjekom mogu krenuti neželjenim tokom. Nešto je očigledno ispušteno iz ruku - kultura, demokratija, čovjek, ili sve zajedno?

Praktična primjena prosvjetiteljskih ideja (demokratizacija obrazovanja i kulture) rukovodi se dobro skrivanom namjerom da se čovjek odrekne vlastitog iskustva i napusti ideju o mijenjaju svijeta, da bi svoju stvarnu životnu situaciju zamijenio jednom imaginarnom. Sasvim paradoksalno, savremena sociologija ovaj proces naziva socijalizacijom. Kultura i obrazovanje se danas koristi kao način socijalizacije u uslovima u kojima se čovjek razdvaja od smisla svog postojanja. Na taj način se dobija još jedan primjer contradictio in adjecto: sve treba da se socijalizuje osim stvarnih društvenih uslova. Jer društvo u kojem se ovakva socijalizacija odvija nije stvaralačko, u najboljem slučaju je 'participativno', to su društva u kojima se istorija „stvara ljudima iza leđa”. Pojedinac i grupe se pozivaju i upućuju na učestvovanje u primanju kulturnih, naučnih, umjetničkih oblika - koje drugi stvaraju - da učestvuju u prihvatanju odnosa u društvu i prilagođavanju tim odnosima - koje drugi određuju - u politici društva koju vode drugi. Njihova uloga se tako, već mnogo puta rečeno, svodi na pukog potrošača duhovnih i materijalnih proizvoda. Takvo stanje se naziva demokratijom! Jedini oblik ispoljavanja bilo kakvog subjektiviteta jeste prilagođavanje. I upravo takvo prilagođavanje, takvo iznuđeno i nametnuto mirenje sa datim okolnostima i odustajanje od bilo kakvih promjena se naziva socijalizacijom!

U antagonističkim društvenim odnosima, prosvjetiteljska ideja o kulturi i obrazovanju kao uzvišenim i humanističkim, preobražava se, čak i kada većina zagovornika ovakvog promišljanja i nema namjeru, u ideju o duhovnom konformizmu. Promišljeni, ali i dobro prikriveni cilj demokratizacije kulture jeste prilagođavanje. Shvatiti ponuđene kulturne oblike i usvojiti masovne, širene i propagirane vrijednosti znači prilagođavati se stanju stvari, oslobađati se napetosti svakodnevnice, prevazilaziti otuđenost i neurotičnost. Kulturi je tako namijenjena uloga da kulturnim, duhovnim, obrazovnim konformizmom, utemeljuje odnosno jača društveni konformizam uopšte.

\section{Značenja socijalizacije}

Izraze socijalizacija čovjeka, sistem vrijednosti i kulturne potrebe možemo čuti danas u gotovo svim raspravama o kulturi. Ovim izrazima, kao i nekim drugim kao što su kulturni identitet, komunikacija, interakcija, pridaju se 
značenja za koja se pretpostavlja da su ključna za razumijevanje savremenih kulturnih događanja. No, važno je ustvrditi protivrječnosti njihovih stvarnih sadržaja i značenja.

Ako se kultura razumijeva kao smišljena društvena djelatnost, onda bi se uslovno mogla izvući dva opšta kulturna obrasca: demokratizacija kulture i kulturna demokratija. Njihova su polazišta i ciljevi sasvim različiti, a posljedice ovih razlika i pogrešnog razumijevanja dalekosežne. Ne samo da se njima daju različiti odgovori na različita pitanja kulturnog razvoja nego se i pitanja u okviru ova dva kulturna obrasca sasvim različito i formuliraju. Kada je riječ o kulturnim potrebama i pravu na kulturu, otvara se pitanje: na koje se tačno kulturne potrebe misli, na već postojeće ili neke nove, ili one u razvoju? Zatim, postavljaju se i sljedeća pitanja: da li pravo na kulturu podrazumijeva zadovoljavanje kulturnih potreba u oblicima i sadržajima 'vladajuće' kulture ili se, prije svega, pitanje odnosi na kulturne potrebe za koje se građani opredjeljuju? Također, iz ovih pitanja proizlaze i naredna: ko tumači i ko zadovoljava kulturne potrebe - građani, društvene grupe kojima pripadaju ili neko drugi u njihovo ime?

Za demokratizaciju kulture, ova se pitanja, recimo, ne postavljaju. Kulturne potrebe su one koje se odnose na pravu kulturu, višu i univerzalnu. Ako se neka pitanja i postavljaju, ona se najviše odnose na praktičnu stranu - kako izgrađivati i širiti potrebe za kulturom a ne za suštinu kulturnih potreba. Može se, dakle, govoriti o strategiji demokratizacije kulture, ili u najboljem slučaju, o 'kulturnoj pedagogiji'. Demokratizacija kulture u svim društvima ne priznaje kulturni pluralizam da bi se za nju ova pitanja uopšte postavljala. Ona propagira i širi monocentrični kulturni obrazac, a to znači da priznaje kulturne potrebe koje se odnose samo na kulturne oblike ovog konkretnog obrasca. Sa stanovišta kulturne demokratije, međutim, ovakva pitanja se postavljaju ne samo zbog kulturnih potreba nego i ostalih pojmova za koje smatramo da su važni za razumijevanje kulturnih procesa: sistemom vrijednosti i socijalizacijom. Ako spomenemo, naprimjer, sistem vrijednosti, automatski pitamo: koji? Jer onaj sistem vrijednosti koji navodno usvaja kompletno društvo predstavlja teorijsku apstrakciju ili, u najboljem slučaju, daleki cilj.

Sa stanovišta stvarnih društvenih iskustava i praksi, moglo bi se govoriti o različitim sistemima vrijednosti - grupa, klasa, lokalne i regionalne zajednice, ali ne i o sistemu vrijednosti jednog cjelokupnog društva. Ali ne priznajući kulturni pluralizam, demokratizacija kulture ne priznaje ni ovaj širi, opšti. Zatim, šta bi trebalo da znači odabir vrijednosti, ako se uzmu u obzir institucije 
preko kojih se vrijednosti neposredno uspostavljaju (škola, porodica, religija, politika, mediji, zakoni), ili posredno putem društvenih, ekonomskih i drugih uslova. Na kraju, treći pojam koji kulturne studije smatraju veoma značajnim, socijalizacija, izaziva dodatne nedoumice. Šta socijalizacija uopšte znači? Da li je to 'prilagođavanje datim uslovima' odnosno 'usvajanje sistema vrijednosti određenog društva', ili nešto drugo? Ako socijalizaciju povežemo sa čovjekovom istorijskom evolucijom, istovremeno možemo postaviti pitanje: da li je takva socijalizacija uopšte moguća putem kulture, samo promjenama u kulturi a ne i promjenama u društvenim odnosima.

Demokratizacija kulture se, kako već mnogi teoretičari navode, temelji na ideji o kulturi po kojoj se kulturni razvoj, kulturne potrebe i vrijednosti i socijalizacija ličnosti posmatraju i razumijevaju kao prevashodno kulturne pojave i dešavanja. Nasuprot tome, kulturna demokratija posmatra i razumijeva kulturne potrebe, vrijednosti, cjelokupan razvoj kulture, u složenoj međusobnoj povezanosti te uslovljenosti s elementarnim zbivanjima u društvu. Iz ovoga proizlazi i najvažnija razlika između demokratizacije kulture i kulturne demokratije, razlika koja se odnosi na suštinu svih događanja i kretanja u jednom društvu, na način obrazovanja i razvoj ličnosti, na tzv. 'proizvodnju ljudi'. Demokratizacija kulture usvaja i primjenjuje prosvjetiteljstvo čije je polazište i ishodište ideja o podučavanju i usmjeravanju. S druge strane, polazište kulturne demokratije je čovjekovo samoostvarivanje, ideja da čovjek stvara društvo i svoju istoriju. Odvajajući kulturne potrebe od društvenog i ekonomskog konteksta i umanjujući uticaj čovjeka na sopstveno formiranje i razvoj, demokratizacija kulture opravdava s teorijske tačke gledišta, ali praktično omogućava manipulisanje ljudima prema potrebama i interesima van dometa samog čovjeka.

Sasvim suprotno tome, kulturna demokratija se zasniva na razumijevanju da čovjek treba da ovlada svim uslovima svog života i rada, da postane „kovač svoje sudbine". Kroz cjelokupna društvena dešavanja i pretpostavimo, kao njihov aktivan sudionik, čovjek bi trebao prvenstveno "sam sebe da stvara" i da stvara kulturu. Demokratizacija kulture se zauzima za usvajanje već postojećih kulturnih vrijednosti i postojećih kulturnih ostvarenja, koji se zatim sistematski dalje šire. Tu kulturu, hipotetički višu ili pravu kulturu, Demerath naziva 'kulturom ugledanja'. Nju stvara manjina dok je velika većina prima na taj način što je podražava da bi na taj način postala „kulturna”. Sve su dosadašnje kulture u istoriji, kako tvrdi Demerath, bile kulture podražavanja. S druge strane, kulturna demokratija na prvo mjesto stavlja kulturu stvaranja, onu u čijem bi stvaranju i razvoju učestvovala većina u društvu. Iz ovoga 
proizlazi da kulturna demokratija ne predstavlja samo usvajanje određenih kulturnih vrijednosti nego predstavlja stvaranje i razvoj uslova u kojima bi se ispoljavale čovjekove sposobnosti i potvrđivao njegov ljudski i stvaralački smisao. Tako bi potreba za stvaranjem mogla vremenom i da postane jedna od primarnih čovjekovih potreba. Zato su za kulturnu demokratiju neprimjereni izrazi: usvajanje kulturnih vrijednosti, pristup kulturi, širenje kulture, zadovoljavanje kulturnih potreba, korisnici kulturnih usluga, kulturni animatori, kulturna proizvodnja, kulturna potrošnja, i drugi iz paternalističko-administrativno-komercijalističkog rječnika demokratizacije kulture. Svi ovi izrazi ukazuju na razdvajanje čovjeka na funkcije, na odvajanje kulture od samog života, na podjelu na one koji kulturu stvaraju i na one koji kulturu primaju, na one koji podučavaju i one koji se podučavaju. Kulturna demokratija treba izgraditi svoje pojmove, svoj rječnik, uvesti one izraze koji će izražavati jedinstvo čovjeka, i njegovih funkcija i njegovih potreba. Da izraze suštinu kulture, ali i suštinu ljudskog postojanja.

\section{Kontradiktornosti kulturnog etatizma}

Kulturna politika koja se rukovodi načelima demokratizacije kulture podrazumijeva smišljene poduhvate da se određene kulturne potrebe ljudi zadovoljavaju, da se pretpostavljene kulturne vrijednosti učine dostupnim što većem broju ljudi (u idealnom slučaju svim članovima u društvu), kao i da se ljudi stvaralački izražavaju u preporučenim kulturnim sferama. Kulturi se stoga u segmentu socijalizacije ličnosti pridaje izuzetno značajna uloga. Nosilac ovakve kulturne politike je (ili bi bar trebala da bude) država kao pretpostavljeni zaštitnik opšteg interesa. Da bi se ovo ostvarilo, država donosi normativne akte, osniva odgovarajuće ustanove, uvodi metode planiranja, razvoja te programiranja kulturnog razvoja. Uporedo s ovim oblikom demokratizacije kulture, ali s nešto drugačijim metodama i ciljevima, djeluje i tržišni mehanizam tzv. privatni sektor. Razvijaju se one kulturne vrijednosti koje tržište prihvata. Ma koliko se razlikovali, čak i bili međusobno konkurentni, ovi podsistemi imaju jedno zajedničko obilježje: i u jednom i u drugom se kulturne potrebe tumače relativno nezavisno od samih građana. Među njima postoji jedna vrsta podjele sfera. Privatni sektor je orijentisan na kulturnu industriju, dok država uglavnom podstiče one segmente u kulturi za koje smatra da su korisni za društvo, a koje privatni sektor napušta jer nisu probitačni ${ }^{3}$.

3 Takav je slučaj sa pozorištima, bibliotekama, razvijanjem kulture u manjim i nerazvijenim zajednicama. 
U svjetlu ovakvih promišljanja, značenje pojmova je veoma složeno. Ako govorimo o kulturnim potrebama, onda se postavlja pitanje kako se one $u$ ovakvim današnjim uslovima mogu ustanoviti kao aktuelne i potvrđivati kao društvene i važne. Pošto i državna administracija, kao predstavnik javnog sektora, i kulturna industrija, kao predstavnik privatnog, posreduju između ljudi i praktičnog zadovoljavanja njihovih potreba, one su u položaju ne samo da na različite načine tumače te potrebe nego i da samim zadovoljavanjem tih potreba preobražavaju te iste potrebe i podređuju svojim interesima. Mjerila ocjenjivanja i tumačenja kulturnih potreba i vrijednosti se ne utvrđuju u demokratskim društvenim procesima jer građani praktično nemaju mogućnosti, ili su te mogućnosti nedovoljne, kako bi sami izrazili svoje potrebe. Oni koji odlučuju o sredstvima za kulturu (administracija, centri političke i finansijske moći) posredno ili neposredno primjenjuju isključivo svoja mjerila, u kojima se izražavaju i njihovi interesi.

U slučaju privatnog sektora, tumačenje kulturnih potreba je djelimično fleksibilnije (znake za prepoznavanje potreba uglavnom određuje tržište), ali s druge strane je još uže, s obzirom da se tržišni mehanizam trudi da zadovolji uglavnom već ustaljene potrebe, ne upuštajući se u finansijski rizik da „,proizvodi” nove kulturne potrebe ili stvara lažne potrebe. To je ono ustrojstvo koje Marcuse naziva ,induciranim potrebama društva”, traženim ponašanjem i poželjnim aspiracijama koje su postale spontane. Ma koliko se po načinima i ciljevima međusobno razlikovali, državni paternalizam i kulturna industrija se veoma lako dopunjuju u procesu izmjene i kontrolisanja čovjekovih potreba i manipulisanju njegovim najintimnijim težnjama, u duhovnom podređivanju ljudi. Drugim riječima, radi se o kulturnom relativizmu, konceptu koji otvara pitanja da li postoje univerzalni standardi odnosno vrijednosti koje bi svi ljudi trebali slijediti, odnosno da li kulturološki relativizam znači da su svi običaji i ponašanja podjednako prihvatljivi. Kriteriji, standardi su difuzni jer se ispostavilo da oni zavise od 'svjesne proizvodnje značenja' koji proizlaze iz različitih diskursa. Različiti diskursi ukazuju na heterogenost svijeta, jer njih proizvode već pomenute različite grupe koji se identifikuju na osnovu različitih i mnogobrojnih karakteristika. Demokratija obezbjeđuje slobodu različitim grupama da stvore i promovišu svoj diskurs, odnosno svoje interese, kulturu, pogled na svijet. Jednom riječju, svoj identitet. Potreba razumijevanja 'drugog' i 'drugačijeg' što se svakodnevno umnožava, najviše zbog komunikacione dinamike, ali i demografskih promjena u cijelom svijetu, postaje imperativ bez čijeg poštovanja složena društva današnjice jednostavno nisu u stanju funkcionisati. Ovim otvaramo i naredno pitanje: kako je moguće 
uopšte imati određeni sistem vrijednosti ukoliko je svaki sistem podjednako prihvatljiv i vrijedan? Na prvi pogled, ovakvo retoričko pitanje nameću novi pristupi i razumijevanja u kulturi, koja se već odavno udaljila od visokih, elitnih oblasti kulture i preselila se u sam centar svakodnevnog čovjekovog života, te političkih igara i manipulacija. Opšta demokratizacija kulture iznjedrila je i sasvim drugačije pristupe u smislu mjesta i uloge kulture u životu svakog pojedinca. Na osnovu raznih modernističkih i postmodernističkih promišljanja i tumačenja, dolazimo do saznanja da svaka društvena grupa, bilo da je dominantna ili marginalna, svaki oblik kulture, odnosio se on na umjetnost, rock kulturu ili kulturu delinkvenata, sekti, etničkih zajednica ili homoseksualaca, predstavlja, derridovski kazano, cjelinu značenja. Visoka, niska, elitna i popularna kultura spajaju se u nove forme koje sve više brišu granice i razlike koje su ih ranije nepomirljivo razdvajale, imajući zajedničku karakteristiku zavisnosti od tržišta. Kič-kultura i umjetnost postaju legitimni kulturološki koncepti kao i svi drugi. Svaki glas, svaki individualni napor može postati relevantan ukoliko u igri promocije učestvuju određeni centri moći i ukoliko je „demokratski ambijent” spreman da prihvati sve i svakog koji želi i ima potrebu nešto da kaže. Na ovakav način, kultura se 'susrela' s odsustvom poretka, oslonca i strukture, do mjere do koje je izgubila mogućnost da pojedincu ponudi smislenu egzistenciju, koja će se oslanjati na neki 'viši smisao postojanja'.

\section{Zaključna razmatranja}

Za današnji svijet, svijet u kojem živimo, kaže se da razvoj kulture i obrazovanja u njemu zaostaju za materijalnim i tehnološkim razvojem. Nikada se jače nije osjećala potreba za uzajamnošću, i nikada razlike između razvijenih i nerazvijenih, između onih koji imaju i koji nemaju nisu bile tako velike i tako izražajne. Uzdrmani su nazori o kulturi, osjećaj pripadnosti, samopouzdanje kulturnih cjelina, konstantno osjećamo da je jedan sistem vrijednosti nepovratno doveden u pitanje, a da ,novi” još nije uspostavljen. Zabrinutost mnogih, u svim dijelovima svijeta, dovodi do poziva na „odbranu” već postojećih ,identiteta”. „Ideološko otrežnjenje” na svjetskoj političkoj sceni u posljednjih dvadeset godina olakšava zloupotrebu pojma kulture i širenje ksenofobijskih ideja.

Odgovor na pitanje da li će u vremenu u kojem živimo, i u kome je svijet isto toliko sposoban za još veći napredak koliko i za samouništenje, biti ostvaren istorijski skok kojim bi se počelo pisati novo poglavlje čovjekove istorije, obavijen je koliko neizvjesnošću toliko i već neskrivenim pesimizmom. Pred 
našim očima odvija se zgušnjavanje istorije, koja sve više proširuje svijest o neophodnosti promjena. Pogled u budućnost, međutim, zamagljuje predstave koje smišljeno šire snage zainteresovane da se tok istorije zaustavi kao i nejasnoće kroz koje se teško probija svijest savremenog čovjeka.

Uporedo s ovakvim političkim i društvenim tokovima, u svijetu se razvijaju, kao njihovo osporavanje i kao drugi mogući izbor, kulturni i politički oblici u kojima se izražavaju težnje širih slojeva društava za slobodama i pravima kao i aktivnim ulogama u politici društava i kulturnom stvaranju. Ovakvi oblici, u očiglednom porastu posljednjih godina, moglo bi biti važan činilac budućnosti u mjeri u kojoj se bude širilo saznanje da osnovni problem našeg vremena nije, u riječima Hannah Arendt, samo ,proizvodnja predmeta za ljude”, već „proizvodnja ljudi za predmete”.

Planetarni talas masovne kulture, ,ekonomska mondijalizacija” i konačno krah ustaljene političke podjele svijeta, oslabivši smisao prihvaćenih simbola, doveli su u pitanje kulturne sisteme. Predstave, ponašanja, navike, ustaljeni oblici razmjene, nastavljaju da se razvijaju bez vjere u institucije koje bi ih simbolizovale, koje bi ih ,,pamtile”, koje bi ih osmišljavale. Stoji pretpostavka da kao društvo u cjelini ne prolazimo samo kroz krizu kulture već i kroz krizu samopouzdanja i samopoštovanja.

\title{
DEMOCRATISATION OF CULTURE OR CULTURE OF DEMOCRACY
}

\begin{abstract}
-Abstract-
Rudimentary questions regarding understanding of culture, education and democracy always emphasize the right of every human being on education and culture. Right on education, culture, and self - acknowledgement and self-validation is the best to observe through manners of their practical attainments or their failures. This observation underlines guesstimate that democracy of culture has generated completely different approaches vis-à-vis the role and position of culture in life of each individual. Furthermore, this article aims to accentuate clear distinction points between two significant social patterns: cultural democracy and democracy of culture.
\end{abstract}

Key words: culture, democracy, illumination (period), socialization, cultural preferences. 


\section{Literatura:}

- Adorno, Theodor W. (1991) The Culture Industry, Routledge, London/ New York.

- Buden, Boris (2007) Vavilonska jama: O (ne)prevodivosti kulture, Fabrika knjiga, Beograd.

- Demerath, Loren (2012) Explaining Culture: The Social Pursuit of Subjective Order, Lexington Books, New York.

- Đorđević, Jelena (2008) Studije kulture, Zbornik, JP Službeni glasnik, Beograd.

- Hartley, John (priređivač) (2007) Kreativne industrije, Clio, Beograd.

- Horkheimer, M., Adorno, Theodor W. (1974) Dijalektika prosvjetiteljstva, Filozofijski fragmenti, Veselin Masleša, Sarajevo.

- Lal, Vinay, Nandy, Ashis, (2012), “'Budućnost znanja i kulture”, Clio, Beograd.

- Marcuse, Herbert (1977) Kultura i društvo, Bigz, Beograd.

- Marx, Karl (1956) Teze o Feuerbachu, prev. Vanja Sutlić. U: Feuerbach, Ludwig: Izbor iz djela (predgovor), Matica hrvatska, Zagreb.

- de Montaigne, Michel, (1977) Ogledi, Reč i misao, Rad, Beograd.

- Sennet, Richard (1989) Nestanak javnog čovjeka, Naprijed, Zagreb. 